Etnográfica

Revista do Centro em Rede de Investigação em

Antropologia

vol. 22 (3) | 2018

Vol. 22 (3)

\title{
Da pata do cavalo ao pé do coelho: razão e sorte no processo de elaboração de apostas no turfe
}

Reason and luck in the process of betting in horse racing in Rio de Janeiro

\section{Rômulo Bulgarelli Labronici}

\section{(2) OpenEdition}

Journals

\section{Edição electrónica}

URL: https://journals.openedition.org/etnografica/5801

DOI: 10.4000/etnografica.5801

ISSN: 2182-2891

\section{Editora}

Centro em Rede de Investigação em Antropologia

\section{Edição impressa}

Data de publição: 1 outubro 2018

Paginação: 481-501

ISSN: 0873-6561

\section{Refêrencia eletrónica}

Rômulo Bulgarelli Labronici, «Da pata do cavalo ao pé do coelho: razão e sorte no processo de elaboração de apostas no turfe», Etnográfica [Online], vol. 22 (3) | 2018, posto online no dia 10 outubro 2018, consultado o 21 janeiro 2022. URL: http://journals.openedition.org/etnografica/5801 ; DOI: https://doi.org/10.4000/etnografica.5801

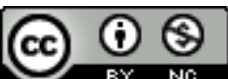

Etnográfica is licensed under a Creative Commons Attribution-NonCommercial 4.0 International License. 


\section{Da pata do cavalo ao pé do coelho: razão e sorte no processo de elaboração de apostas no turfe}

\section{Rômulo Bulgarelli Labronici}

As corridas de cavalo, denominadas de turfe, se apresentaram como um objeto expoente para observar e analisar questões referentes aos jogos de apostas praticados na cidade do Rio de Janeiro. A comunhão entre um espetáculo esportivo e um mercado de jogos de azar produz nas corridas do turfe possibilidades de os jogadores participarem das corridas de forma ativa, mediante a constante produção de apostas. As denominadas casas de apostas se estabelecem como espaços estratégicos que possibilitam um acompanhamento cotidiano dessa atividade. Os apostadores do turfe utilizam diversos saberes num intricado e complexo processo classificatório, com elementos ditos "intuitivos" ou "racionais". Para um apostador experiente, a utilização de informações, conhecimentos e saberes referentes a técnicas específicas é essencial para a produção de um bom jogo; as suas avaliações envolvem tensões permanentes entre disputas e colaborações, obrigações e deveres, armadilhas e solidariedades. Em conjunto, esses fatores podem ser representados como gradações de uma "ciência". Esta parece pretender deixar pouca margem para o acaso, mas também se deixa cercar por "magia”, uma vez que há sempre uma variável, um aspecto ou dimensão que se admite deixar escapar no processo de conjunção entre dados e intuições.

PALAVRAS-CHAVE: jogos, apostas, turfe, sorte, Rio de Janeiro.

Reason and luck in the process of betting in horse racing in Rio de Janeiro - Horse races may be seen as a privileged stance to observe and analyze questions regarding betting practices on the streets of Rio de Janeiro. The communion between a sports spectacle and a gambling market produced in the turf enables gamblers to actively participate in races through the constant production of bets. The so-called "bookmakers" are strategic spaces that allow for the daily monitoring of this activity. Horse racing gamblers use an intricate and complex classificatory process to establish their bets, especially involving both "intuitive" and "rational" elements. For an experienced gambler, the use of information, knowledge and knowhow related to specific techniques is essential for the production of a good bet. Evaluations are endowed with permanent tensions between disputes and collaborations; obligations and duties; traps and solidarity. Gathered together, they can be seen as gradations of a "science." This seems to leave little room for chance, but it also surrounds itself with "magic," since there is always a variable, aspect or dimension that is conceived to escape in the process of conjunction between data and intuition. KEYWORDS: games, bets, turf, luck, Rio de Janeiro.

LABRONICI, Rômulo Bulgarelli (romulolabronici@gmail.com) - INCT-InEAC, Universidade Federal Fluminense, Brasil. 


\section{INTRODUÇÃO}

As corridas de cavalo, denominadas de turfe, se apresentaram como um objeto expoente para observar e analisar questões referentes à compreensão de jogos de apostas praticados nas ruas da cidade do Rio de Janeiro. ${ }^{1}$ A comunhão entre um espetáculo esportivo e um mercado de jogos de azar produz nas corridas do turfe possibilidades para que jogadores participem das corridas de forma ativa, mediante a constante produção de apostas. Aqui, as denominadas "casas de apostas" se estabelecem como espaços estratégicos que possibilitam um acompanhamento cotidiano dessa atividade. ${ }^{2}$ Este trabalho utiliza como base uma pesquisa de campo com grupos de apostadores que visou um acompanhamento etnográfico em casas de jogo espalhadas pela cidade do Rio de Janeiro. Este acompanhamento buscou observar como jogadores se relacionam com o jogo e com os seus pares para a elaboração e construção de uma aposta, transformando o espaço em uma arena de sociabilidade mediada pelas práticas de jogo.

O hábito de apostar em locais públicos no Rio de Janeiro se apresenta de tal modo que é possível encontrar espaços onde há concentrações de pessoas, em sua grande maioria homens, apostando em diversos tipos de jogos. Com idades avançadas e cabelos brancos, estes indivíduos interagem entre si e pouco se incomodam com os transeuntes e passantes que porventura possam atravessar os espaços destinados para a jogatina. Bebidas e cigarros são complementares e consumidos no local, enquanto que o jogo, com ou sem apostas em dinheiro, é o foco central da atenção da maioria dos presentes.

O objetivo aqui é descrever e analisar como os apostadores do turfe utilizam saberes a partir de um intricado e complexo processo classificatório para apostar, principalmente no que tange processos ditos "intuitivos" e "racionais". Para um apostador experiente, a utilização de informações, conhecimentos e saberes referentes a técnicas específicas é essencial para a produção de um bom jogo. Da mesma forma, conhecer em detalhe como os efeitos e relações ligados ao conceito de sorte influenciam esse processo torna-se essencial para um entendimento dessa prática. Os apostadores em corridas de cavalos são sujeitos sociais que levam a sério seu "ofício". Para estes, observar cavalos, ler sobre eles, saber quem os cria, onde e como são tratados, entre muitos outros aspectos, se conjuga com as histórias contadas sobre esse conjunto

I Este artigo resulta da pesquisa de doutorado em antropologia, financiada pela Coordenação de Aperfeiçoamento de Pessoal de Nível Superior (Capes) e desenvolvida no quadro institucional do Programa de Pós-Graduação em Antropologia da Universidade Federal Fluminense (PPGA/UFF). É válido destacar que o título contém dois traços importantes: "pata do cavalo", sinônimo para apostas no turfe, e "pé de coelho" um símbolo que remete a sorte.

2 As casas de apostas do turfe são oficialmente agentes credenciados do Jockey Club Brasileiro e costumam ser também abreviadamente denominadas de "lojas" pelos seus frequentadores. 
de indivíduos e animais, como apontaram diversos autores (Barcelos 2001; Cassidy 2002, 2007; Velasquez 2015), em especial aquelas contadas por seus pares, aqueles com quem se joga. Perscrutando os mistérios que atraem aqueles homens, sobretudo no âmbito das corridas de cavalo, busco apresentar um universo social constituído a partir da dimensão da instrução complementar de avaliações pragmático-racionais e simbólico-culturais (Sahlins 2003). Essas avaliações são dotadas de tensões permanentes entre disputas e colaborações, obrigações e deveres, armadilhas e solidariedades. Reunidos em conjunto, esses fatores podem ser representados como gradações de uma "ciência", que parece pretender deixar pouca margem para o acaso, mas também se deixa cercar por "magia", uma vez que há sempre uma variável, um aspecto ou dimensão que se concebe deixar escapar no intrincado processo de conjunção entre dados concretos e intuições.

Assim, é válido perguntar: o que está efetivamente sendo jogado? A primeira imagem que aparece é que, no jogo, aposta-se bens materiais, mais especificamente, dinheiro. Entretanto, para além do uso de dinheiro, este trabalho busca entender os espaços de jogo como ambientes imbricados em constantes trocas e associações, não apenas materiais, mas também simbólicas. Informações, palpites, pressentimentos e sorte são elementos constitutivos das trocas em uma casa de jogo e serão utilizados para apostar e adquirir prestígio perante os pares. Com isso, são conjuntamente realizados processos que levam em consideração o inexplicável, ou aquilo que não é passível de uma comparação direta entre uma aposta e outra. Espera-se que um jogador tenha um olhar diferenciado e saiba enxergar o universo do turfe por meio de outras lentes e que saiba avaliar até mesmo onde está o peso de sua própria sorte.

\section{A SORTE COMO ELEMENTO DE ESCOLHA}

Ter uma boa leitura do jogo e saber avaliar o momento, as condições do animal e o treinamento, assim como as demais variáveis inseridas no universo do turfe, são traços valorativos de um bom jogador. Todavia, tais processos de avaliação muitas vezes perpassam também pela subjetividade de cada um, criando múltiplos sistemas de representação e classificação de cada páreo. ${ }^{3}$ Deste modo, por uma questão analítica, aponto para a existência de dois processos equivalentes nesse sistema: um da ordem do simbólico (ou cultural) e outro da ordem da experiência (ou racional), ambos relacionados na classificação para a elaboração de "palpites". Os processos de avaliação denominados sensíveis

3 A distribuição das corridas em páreos possibilita que um jogador realize suas apostas de maneira que possa organizar individualmente seu próprio jogo. Cada prova no turfe é realizada de modo a apresentar um número limitado de competidores previamente organizados numericamente. Para se estruturar um páreo, é necessário que se tenha um número mínimo e máximo de cavalos inscritos. 
seriam os que levam em consideração dados mensuráveis e verificáveis entre os apostadores (cf. Lévi-Strauss 1973). O antropólogo Marvin Scott (1968), ao buscar o que denominou de "problema da racionalidade", apresenta como essa questão é entendida nas pistas de corrida do turfe americano. Ao contrário de uma resolução estatística simplificada, a produção das apostas advém de dois postulados etnográficos: o primeiro é dado pelas corridas em si e o segundo pelas arenas de sociabilidade entre jogadores, que a utilizam para a definição de suas apostas. Entender a racionalidade aqui consiste em compreender o objeto de construção dentro dessas arenas. Enquanto que uma corrida seria entendida, no espírito de Heráclito, como um acontecimento único ocorrido em uma coordenada específica do espaço/tempo, as arenas de sociabilidade de jogadores seriam espaços onde ela faria sentido lógico:

"Observando esta arena, encontramos vários tipos de participantes que agem com base em suas informações sobre os cavalos e as chances afixadas no quadro de apostas. Sua decisão de apostar repousa sobre as chances que eles constroem a partir de seus sentimentos, do resultado provável da corrida e das probabilidades publicadas. Os apostadores, em seguida, recorrem às histórias dos diferentes cavalos e às atividades de seus colegas apostadores" (Scott 1968: 177).

Assim, a objetividade na classificação de um páreo pode ser encontrada comparativamente a partir de uma série de dados calculáveis, como, por exemplo: o número de vitórias anteriores de cada competidor, o tempo realizado na prova, a distância percorrida nas últimas corridas ou sua atuação em provas de grupo (consideradas mais concorridas, com um maior grau de dificuldade e de maior prestígio). Assim, a avaliação racional se apresenta como uma lógica de ponderação do passado de cada competidor, com características pretensamente racionais, de modo a estabelecer parâmetros classificatórios para as corridas futuras.

Por outro lado, a racionalidade numérica/estatística não é a única forma de avaliação de um páreo. Processos de avaliação denominados aqui de culturais estão conjuntamente inseridos na elaboração de palpites e possuem uma relevância equivalente à dos processos racionais. Por se tratar de uma atividade na qual homens e cavalos correm, as análises das performances no turfe não podem ser exclusivamente feitas "no papel” (através de uma organização mensurada pela racionalidade matemática). De forma que, mesmo que um dos competidores possa a priori ser considerado melhor do que os demais, isso não implica em garantias de vitória. Tendo esta noção em mente, jogadores não deixam que os dados puramente objetivos de avaliação sejam exclusivamente determinantes para a definição de uma aposta. Com isso, são conjuntamente realizados processos que levam em consideração outros sentidos. "Gostar" de 
um cavalo em detrimento dos demais, "achar" que vai ganhar, "sentir" que é a hora do cavalo vencer, são traços de avaliação baseados em uma outra ordem, a dos sentidos e (pres)sentimentos. A elaboração de "palpites" atravessa um sistema de avaliação e classificação de cada páreo que envolve traços simbólicos para a realização de uma aposta. Isso se dá pela forma como são entendidos os "palpites" na casa de jogo, que se apresentam como a base de todas as apostas.

Um "palpite" pode ser entendido como um pressentimento ou uma intuição, que pode advir de diferentes fontes, podendo elas serem subjetivas, objetivas ou até mesmo coletivas, oriundas de debates com outros jogadores. Independentemente de sua forma de aquisição, um palpite constitui a definição da escolha de um jogador, e é o primeiro e último passo antes da realização de uma aposta. Não possui a obrigatoriedade de ser jogado, pois um jogador que tenha um palpite pode eventualmente não apostá-lo, embora na maioria das vezes o faça. Ele é elaborado (ou adquirido ou até mesmo construído) antes do jogo e até minutos antes da largada poderá ser modificado. A partir do momento em que um jogador realiza a aposta, um palpite se tornará o "seu jogo". Mesmo sendo transformado em jogo, ele somente deixa de possuir a característica de incerteza no fim do páreo com a comprovação de vitória ou de derrota. Assim, até o término de uma corrida, ele continuará a ser apenas um "palpite", sendo efetivamente jogado ou não.

Com isso, o olhar diferenciado de cada jogador vai proporcionar que ele consiga adquirir palpites por meios intuitivos alcançados por intermédio também da sorte. A sorte, neste caso, se apresenta como uma força individual e é dotada de uma propriedade positiva. Somente com um olhar treinado o jogador saberá avaliar a totalidade das variáveis envolvidas em cada corrida, incluindo a avaliação da própria sorte. Saber avaliar se está com sorte pode ser tão importante como uma avaliação objetiva de um páreo. Ela poderá ser a última fronteira entre uma vitória ou uma derrota no turfe, e um jogador experiente saberá medir o peso que a sorte trará em cada uma de suas jogadas. Apesar de as corridas hípicas não serem consideradas jogos cujo desfecho é decidido pela sorte, ela possui uma função sui generis dentro desta atividade.

A exemplo, apresentamos o caso do jogador Choppinho. ${ }^{4}$ Assim como a grande maioria dos apostadores, Choppinho realiza costumeiramente a totalidade de suas apostas antes do início do primeiro páreo. Chega antes de a casa de apostas abrir e troca informações e "palpites", debate com seus companheiros de jogo sobre as corridas que ocorrerão no dia. Em seu primeiro páreo, Choppinho havia realizado um jogo de "placê" dos cavalos 2 e $4 .{ }^{5}$ Entretanto, a

4 Os apelidos e nomes aqui apresentados foram mantidos como utilizados pelos jogadores em seu dia-a-dia com as corridas.

5 Teoricamente, o "placê" é a aposta que oferece maior possibilidade de acerto. O apostador escolhe um cavalo e ganha se ele chegar em primeiro ou em segundo lugar no páreo. Com essa modalidade, [continua] 
partir de um debate com um de seus companheiros, deixa-se levar pela opinião alheia e modifica sua aposta. Para sua frustração, os cavalos 2 e 4 realizam, respectivamente, uma performance incontestável, sendo mais rápidos que seus adversários, e terminam a prova com uma evidente vitória.

Começar o dia de reunião do turfe com uma derrota não é incomum para um jogador de corridas de cavalos; no entanto, pelo modo como este caso específico ocorreu, Choppinho passa a desacreditar na totalidade de seu jogo. O equívoco na opção pela mudança no primeiro páreo foi transformador, e sua postura passou de um torcedor animado e falante para um jogador triste e desacreditado: "Hoje eu não vou ganhar nada! Olha o que eu fiz! Eu tinha o 2 e o 4 na primeira! Quando acontece isso, não tem jeito. Vou ficar aqui só até acabar com a minha cerveja e sair pra ver o jogo de futebol em outro lugar".

Por mais que o desdobrar de um único páreo não interfira no dos demais, ${ }^{6}$ essa derrota foi o suficiente para que Choppinho perdesse a crença na potencialidade positiva oriunda de sua sorte. Para ele, a sorte não estaria do seu lado naquele dia. A partir da primeira derrota, ele não torceu mais para nenhum de seus jogos e a cada páreo perdido suas lamúrias confirmavam que aquele dia ele não ganharia devido ao equívoco inicial.

Deste modo, as apostas podem ser acionadas a partir de um vínculo criado pelo jogador com seu palpite. Não se trata meramente de algo pontual, de uma determinada aposta, mas de uma relação que se expande para a essência da sorte do jogador no momento jogado e que pode alterar-se abruptamente à medida que os páreos se desdobram. A sorte é apresentada como algo que cada jogador possui individualmente e se manifesta sob diversas formas - um (pres)sentimento, uma inquietação, um sinal - e que é passível de ser transmitida e perdida, caso o jogador não saiba respeitá-la de maneira adequada (Douglas 2010 [1979]).

O fato de perder ou ganhar, saber mais ou menos, não necessariamente exclui a ação da sorte e sua centralidade nessa questão. Por mais que o jogador tenha um papel ativo, a partir de sua liberdade de escolha, a sorte será também mais uma das fontes que os jogadores utilizarão para jogar. Mesmo o jogador Choppinho sendo um dos grandes defensores da ausência de sorte nas carreiras hípicas, é um dos que fazem questão de sempre sentar no mesmo

[continuação] o jogador pode galgar uma vitória com um segundo lugar. Um jogo de "placê" é estabelecido em momentos nos quais os jogadores reconhecem ter poucas certezas no páreo.

6 Excetuando os jogos de acumulados. Neste caso, jogos de acumulados são apostas, de dois ou mais cavalos, nas modalidades de "vencedor", "placê", "duplas" ou "exatas", de páreos distintos. As acumuladas combinadas poderão indicar, por páreo, um ou mais cavalos nas modalidades de "vencedor" ou "placê", ou indicar uma ou mais duplas ou exatas por páreo, sendo que, caso a primeira indicação seja vencedora, o valor inicial apostado multiplicado pelo rateio do páreo será aplicado nas indicações do páreo seguinte e assim sucessivamente. Esta modalidade possui um limite máximo de R\$ 1500,00 para apostas acumuladas de "vencedor" e "placê", e um limite de R\$ 1000,00 para acumuladas de dupla. 
lugar durante as corridas. Sua relação espacial com o lugar onde ele se situa com os seus resultados nas corridas mostra como a percepção da sorte não está completamente ausente.

Contar com a sorte nas casas de jogo não é algo incomum, e essa questão das explicações das fortunas e dos infortúnios pode ser observada sob diversos aspectos. Um deles se encontra na ótica teleológica ou metafísica de definição de resultados. O autor Thorstein Veblen (1994 [1899]) afirma em seu estudo econômico sobre a classe dominante que uma das bases de todo jogo de apostas é a necessidade de se ter uma crença na existência da própria sorte. Segundo ele: "Na sua forma mais simples, a crença na sorte é este sentido instintivo de que existe uma propensão teleológica inescrutável nos objetos ou situações" (Veblen 1994 [1899]: 280). A sorte, também denominada de simpatia, ou superstição, é vista aqui como algo inerente a um objeto, entidade, evento ou pessoa, e é dotada de um "índice de agência" (Gell 1998) superior e fora do controle do jogador. Sob a ótica da ação individual, a sorte poderia ser dotada de propriedades que refletem determinadas ações (ritualizadas) dos jogadores, sendo parte integrante de sua vitória ou de seu fracasso - como, por exemplo, sentar sempre no mesmo lugar durante as reuniões do turfe (como no caso de Choppinho), usar uma mesma peça de roupa durante o jogo (a famigerada cueca da sorte), ${ }^{7}$ ou refazer algo que porventura tenha sido realizado em um momento no qual se tenha tido êxito. Em resumo, ocorre a união automática de eventos a priori desconexos, mas que através da noção de sorte estabelecem conexões entre si e se tornam dotados de sentido para o apostador e para o desfecho favorável (muitas vezes determinante) de seu jogo. Dotada de uma capacidade de potência ou poder de realizar algo, ela se constitui como uma organização da realidade a partir de experiências culturais (Sahlins 2003). Esta propriedade no jogo se constitui de modo que ela pode ser encontrada também intuitivamente, como explicitado na fala do jogador Cumprido:

“Tem horas que não dá pra ficar calculando muito não, ficar estudando pra caralho também dá merda. Às vezes você sabe que um cavalo vai ganhar, aí tem que jogar nele! Pode até ser um azarão da porra, mas você tem que ir. Se você não jogar aí mesmo [é] que ele vai ganhar e te deixar puto!" 8

7 A cueca, o chapéu, ou qualquer outra vestimenta "da sorte" se transforma em um totem do jogador. O objeto absorve as experiências positivas e emana poderes - ou, como antropólogos clássicos, definiriam, partilha do mana ou baraka (Douglas 2010 [1979]: 136) - que são transmitidos pelo contágio e pelo contato. Estar em presença da sorte leva o jogador a obter êxito através dela. É por esta razão que tais vestimentas não devem ser lavadas em hipótese alguma, sob o risco de se lavar também a sorte embebida nelas.

8 O "estudo" do programa é o ato de ler e analisar classificatoriamente todos os dados apresentados nos páreos do programa. Em geral não é realizado com apenas um páreo, mas a partir da totalidade dos páreos de uma reunião. 
Ir contra a vontade da sorte e não obedecer aos indícios que ela apresenta gera o efeito oposto. A sorte pune o jogador que não obedece aos seus sinais, como exemplificado na fala de Cumprido e no relato de Choppinho. Do mesmo modo, é entendido pelos turfistas que não se deve distribuir palpites abertamente para os demais jogadores, pois com isso corre-se o risco de distribuir com eles a vitória e a sorte. Sendo assim, é necessário saber obedecer-lhe. Estar atento aos indícios e às formas manifestas pelas quais ela se constitui é parte integrante da postura de um jogador para chegar a resultados favoráveis. Tal relação envolve uma etiqueta no ato de apostar, entre o jogador e os limites do seu entendimento do papel da agência da sorte no jogo.

O papel da sorte não se restringe apenas ao ato de apostar. Ela pode ser observada também na disputa e na competição. Um cavalo e seu jóquei "azarões" podem "dar sorte" e se consagrarem campeões de uma prova, mesmo quando as condições "lógicas" e "objetivas" são desfavoráveis. ${ }^{9}$ Neste caso, a sorte é observada sempre ao final da corrida e considerada como o fator determinante para o sucesso. O autor Roger Caillois (2001 [1958]) em seu trabalho elaborou uma classificação de tipos de jogos, atribuindo ao estudo do jogo uma importância cultural equivalente à dos estudos de economia, política, religião e instituições familiares. Para ele, as práticas de competição (classificadas por ele como agôn) e as de sorte (alea) possuem uma relação oposta, mas complementar:

"Como o resultado de agôn [competição] é necessariamente incerto e, paradoxalmente, deve aproximar-se do efeito da pura sorte, assumindo que as chances dos concorrentes são tão iguais quanto possível, segue-se que cada encontro com características competitivas e regras ideais pode se tornar o objeto de apostas, ou alea [chance, sorte], por exemplo, corridas de cavalo ou cães de raça, futebol, basquetebol, e brigas de galos. Acontece mesmo com as apostas de mesa, que variam incessantemente durante o jogo, de acordo com as vicissitudes de agôn" (Caillois 2001 [1958]: 18).

A complementaridade nestas duas concepções de jogo estaria na suposta e idealizada equivalência de igualdades iniciais. Tanto em um jogo de dados como em uma competição esportiva, todos os competidores teriam as mesmas chances ideais de vencer. ${ }^{10}$ Mesmo na disputa física, envolvendo atributos

9 Um cavalo denominado de "azarão" é aquele que, comparativamente com os demais competidores, adquire um status de perdedor, apresentando, portanto, menores chances de vencer seus concorrentes. Tal avaliação é realizada antes do princípio do páreo e a partir das leituras dos apostadores. Uma estratificação é realizada entre os cavalos concorrentes e aos apostadores que escolheram o "favorito" é pago um valor menor de premiação, enquanto que aos que escolhem o menos favorito ou "azarão" é paga uma premiação maior.

10 Obviamente, em se tratando de uma corrida no turfe não estou tratando de uma disputa idealizada, mas de uma competição real. Nas carreiras hípicas, competidores terão, a priori, condições [continua] 
como força, destreza, aceleração e velocidade, a noção de sorte estaria presente e influenciaria os resultados.

Apesar da individualidade deste conceito nas casas de jogo, ela pode também ser observada coletivamente. Não é necessariamente sozinho que se faz a avaliação de um páreo ou que se joga. Jogos elaborados em conjunto são outra forma de aumentar o valor gasto em uma única aposta sem que seja necessária uma ampliação do gasto total. O relato do caso entre os jogadores Cumprido, Cabeleira e Gigante exemplifica este ponto.

Cabeleira, conhecido por jogar valores elevados, apresenta a Cumprido um palpite certeiro que entraria no quinto páreo do programa da Gávea, uma égua que, segundo ele, estava: "soltando fogo pelo rabo, voando igual a um foguete”. Desconfiado, Cumprido discute com Cabeleira para avaliar as razões objetivas de seu favoritismo e decidir se jogaria ou não. $O$ jogador Gigante, que não participa ativamente da discussão, presta atenção em seu desfecho e resolve participar em parceria em um jogo coletivo a três. Por fim, os três entraram com o dinheiro para a realização do jogo. Entretanto, a corrida é finalizada com um resultado negativo e Cabeleira passa o resto do dia chamando a égua de "arrombada" e comentando sobre o "jogo perfeito" e que foi "jogado no lixo" pelo animal. Gigante, por sua vez, também visivelmente decepcionado, contentava-se em lamentar: "Pra que fui escutar esses caras? Bando de azarão!"

Após compartilhar o jogo que veio a ser derrotado, Gigante expressa sua frustração de ter se deixado influenciar e partilhar saberes que não são os seus. Nos jogos compartilhados, compartilha-se saberes, experiências, dinheiro e inclusive a própria sorte. E, no caso de uma derrota, a frustração encontra-se na maioria das vezes inscrita nas escolhas e avaliações dos companheiros, acusados de serem protagonistas no desvirtuar da avaliação da corrida e de trazerem influências negativas para o seu desfecho.

Este tipo de compartilhamento, em geral, evidencia alianças e laços fortes entre alguns dos jogadores que porventura tenham uma relação de afinidade ou vínculos mais íntimos de amizade. Pois não se compartilha jogo com quem não se conhece, assim como não se compartilha a experiência nem a sorte com qualquer um. Na vitória ou na derrota, os jogadores estarão juntos e os valores pagos e recebidos por cada um são discutidos antes do início da corrida, a fim de se evitar conflitos. Do mesmo modo, jogadores com desavenças podem

desiguais de sucesso. Cavalos com possíveis problemas de saúde e até mesmo possuidores de uma genética desfavorável serão considerados "favoritos" ou "azarões" a partir das leituras de cada páreo. Entretanto, por não se tratar de uma atividade onde o resultado é adquirido através de uma lógica matemática cartesiana, mas sim de uma disputa entre homens e seus animais, os resultados ainda estão embebidos pelas vicissitudes da disputa. O que gera uma inexatidão que somente será definida após todos os competidores cruzarem a faixa final. Assim, a vitória de um azarão e a derrota de um favorito se tornam partes constitutivas do jogo. 
nunca compartilhar jogos, pois, além de não terem laços constituídos, terão no prazer de ganhar a seu rival mais uma das motivações para o jogo.

Por outro lado, discutir abertamente em alto e bom som para que todos possam ouvir e deixar em aberto que outros jogadores possam participar conjuntamente é menos usual do que o relato acima fez parecer. Em geral, ao montar uma aposta conjunta, os jogadores mantêm um nível de sigilo que não é aberto a todos os presentes, o que faz com que alguns possam até mesmo se afastar momentaneamente da casa de apostas para discutir o palpite, o animal, os valores envolvidos, dívidas e demais questões que porventura possam estar ligadas ao jogo, haja vista que outro jogador presente possa "roubar" (consciente ou inconscientemente) o palpite e refazer o jogo para si. Deixar displicentemente que outros possam se utilizar de seus palpites é uma postura que deve ser evitada. Da mesma forma, não se deve usar os palpites dos outros sem o devido consentimento.

Exemplifico com uma situação ocorrida com o jogador Verdura. Na casa de apostas do Bairro de Fátima, no centro da cidade do Rio de Janeiro, encontro Verdura, que após alguns minutos de conversa pergunta: "Tá com dinheiro aí? Bota cinco [R $\$ 5,00]$ e casa aqui com o meu pra gente fazer um jogo". Olho para a tela da transmissão da corrida e pergunto: "Qual páreo, o quinto da Gávea?" - "Esse mesmo. Tô com uma boa aqui. Bota lá: placê do 3 e 12, dez $[\mathrm{R} \$ 10,00]$ ".

Imediatamente, ao mencionar o seu jogo para mim, foi possível escutar um outro jogador realizando uma aposta que também incluía o décimo segundo cavalo do páreo. Na mesma hora, Verdura me puxa pelo braço e fala:

“- Calma. Vem cá, tira o 12.

- Por quê, Verdura? Não era a boa?

- Não, quando outro joga assim eu prefiro nem jogar. Tira o 12 e coloca o 8".

Embora o jogo original de Verdura incluísse o $12 .^{\circ}$ cavalo do páreo, ao perceber que outro jogador desconhecido realizou simultaneamente uma aposta similar, Verdura retira seu palpite e remonta sua jogada com outro cavalo. Por mais que a aposta do jogador não fosse diretamente escolhida a partir da preferência de Verdura, a semelhança dos jogos e a coincidência de terem sido realizados no mesmo momento foi o suficiente para fazer Verdura mudar de ideia. Assim, a aposta, observada pela chave da sorte, pode ser entendida como tendo maior força quanto mais restrita e mais individualizada for.

O segredo atrelado à forma como os jogadores tratam seus palpites antes de uma corrida passa também pela ideia da sorte, por mais que jogadores como Choppinho afirmem: "Isso aqui não tem nada a ver com a sorte. Se fosse sorte, 
os que ganham não estariam ganhando sempre. Pelo menos mais vezes do que os que perdem. Tem que estudar, muito, tem que saber ver os cavalos e fazer um jogo decente, se não não dá!"

Choppinho explicita que o jogo no turfe não pode ser pautado exclusivamente por uma aleatoriedade definida passivamente pelo apostador. Por mais que, em sua maioria, os apostadores não tenham condições de influenciar o desdobramento de uma corrida, sua participação não é vista sob a ótica da passividade completa. Os saberes tidos como essenciais para se realizar uma aposta e que possibilitam as escolhas dos jogadores são formas de observar os próprios jogadores como agentes ativos do turfe.

As disputas envolvendo cavalos possibilitam que apostas distintas entre os participantes sejam elaboradas; no fim, os cavalos correm e os homens jogam, possibilitando que cada jogador escolha um cavalo distinto. Esta forma de jogo possibilita que sentimentos de posse sejam estabelecidos entre o jogador e a sua aposta. O cavalo escolhido torna-se o "meu" cavalo, a "minha" aposta, estabelecendo um sentimento de posse temporário que amplia a disputa entre os jogadores. A partir das análises simbólicas, e principalmente, racionais de um páreo, as qualidades individuais do apostador são transubstanciadas na aposta. Os ganhos de um jogador refletem o quão melhor ele é sobre os demais. Deste modo, as disputas entre os cavalos servem para confirmar as disputas entre os homens e a aposta vitoriosa é a confirmação da superioridade do apostador.

A postura de Choppinho de negar o papel determinante da sorte é coerente, no sentido de afirmar que o que está em jogo não é apenas uma aleatoriedade ou ganhos materiais. Os reais objetivos nas disputas das casas de jogo devem ser entendidos a partir de qual dos presentes se constitui como o melhor jogador. Sobressair é ser reconhecido como o "conhecedor de cavalos", o "cara que entende", o que "joga muito" - e isso é uma das bases fundamentais na obtenção de prestígio no grupo. A sorte não seria um atributo ideal para comparação. No momento da disputa, a ação da sorte, por não poder ser mensurável, é desconsiderada ou, muitas vezes, negada por completo.

Assim, ganhar por intermédio da sorte, ao contrário do que possa parecer, é algo extremamente danoso para a reputação de um jogador. A acusação de se "ganhar na sorte" traz descrédito e desqualifica qualquer tipo de vitória que um jogador possa ter sobre os demais, pois seria o mesmo que afirmar que ele não possui os atributos necessários de um bom jogador, é um indivíduo que ganhou apenas pelo acaso e não por suas qualidades individuais. Se Choppinho assumisse o papel relevante que a sorte possui nas casas de jogo, ele estaria desqualificando a si próprio como um jogador experiente, pois seria equivalente à afirmação de que algo ocorre acima de suas aptidões de análise e escolha. Equivaleria a afirmar que a influência da sorte em suas vitórias seria superior às suas capacidades de ação. 
(IN)FORTUNAS, OU DERRUBADAS E BARBADAS

Assim como outros esportes, o turfe possui seus especialistas, que comentam sobre as corridas horas antes do início do primeiro páreo do dia. Nos programas chamados "mesas-redondas" é apresentado um balanço geral da situação dos cavalos, que aborda retrospectos, situação dos jóqueis, treinadores e outros possíveis aspectos, como a condição dos haras, studs e etc. Ao final, os apresentadores e comentaristas expõem seus palpites sobre os favoritos a vencedores dos páreos. ${ }^{11}$ Em geral, as mesas-redondas ocorrem horas antes do início dos páreos e são momentos nos quais as casas de apostas não se encontram abarrotadas de apostadores. Esta baixa adesão do público surtiu uma surpresa inicial, haja vista que é a partir da aquisição das mais variadas informações que os jogadores constroem suas apostas. Deste modo, qual seria o motivo pelo qual os jogadores não levam em consideração, e de maneira sistemática, a opinião dos comentadores e "especialistas" para que façam uma melhor avaliação dos páreos do dia? Um dos propósitos do programa seria, para além de propagandear o esporte, contribuir com uma avaliação “objetiva” e completa, com mais variáveis sendo levadas em consideração. Ao realizar tal indagação aos poucos presentes na hora em que uma mesa-redonda era televisionada, o jogador João responde taxativo: "É porque eles derrubam muito!" O termo "derrubador" é muito recorrente nas casas de jogo. Seu significado remete ao ato de derrubar, fazer o outro cair. É possível ainda alargar o sentido da expressão, por analogia, ao "cair do cavalo" durante uma corrida. Assim, no âmbito das apostas, o "derrubador" é aquele que de alguma forma faz intencionalmente o outro jogador perder em detrimento de algum benefício próprio. Ao lidar com um jogo de apostas, trata-se diretamente com incertezas e emoções oriundas destas incertezas, e um "derrubador" pode ser entendido como aquele que intencionalmente manipula as incertezas de modo a fazer o outro perder, ainda que, muitas vezes, não tenha ele próprio uma noção clara e objetiva de como fazê-lo. Na busca por entender o real significado desta categoria de acusação (Velho 2004), continuo com a indagação de João, que complementa:

"Eles vão chegar e falar: 'Esse é a primeira força, segunda força e terceira força e coisa e tal'. ${ }^{12}$ Muitas vezes eles são cheios de conchavo. A maioria

11 O historiador Victor Melo (2001: 167) evidencia que, desde meados do século XIX, os clubes de turfe utilizam espaços midiáticos, como colunas de jornais, para a divulgação de palpites, devido aos altos volumes de jogo. Atualmente as mesas-redondas são emitidas pela TV Turfe (canal 13 da NET), com eventuais aparições no caderno de esporte de alguns jornais de grande circulação.

12 A expressão "primeira força" é referente ao cavalo mais forte, o que se acredita ter mais chances de ganhar um páreo, "segunda força” ao segundo, e assim por diante. Em geral, esta expressão é usada apenas para os primeiros cavalos, não chegando a ser usada para os cavalos mais "fracos", ou com menos força. 
do que eles falam não presta. Tem uns que têm contato com um treinador, com um dono, aí ficam forçando pra um lado ou para o outro. É muito tendencioso".

De certo modo, o termo "derrubador" explicita um conflito de interesses entre jogadores em um determinado páreo e denota uma malandragem utilizada por uma das partes envolvidas. Assim, jogadores são taxados de "derrubadores" por convencer o outro a apostar em um jogo a partir de palpites tidos como tendenciosos.

Um dos "truques" mais difundidos entre os "derrubadores" é a distribuição de palpites para o número de apostadores equivalente ao número de cavalos no páreo. Assim, um derrubador convence outros jogadores, acionando argumentos inscritos na lógica do jogo ou apresentando supostas informações privilegiadas adquiridas por terceiros, sobre um cavalo com melhores chances de vitória. Ele buscará fazer isso quantas vezes for capaz, preferencialmente apresentando no mesmo páreo um cavalo diferente para cada jogador inscrito em círculos de amizades distintos. Nas carreiras do turfe, só pode haver um único cavalo vencedor; então, a maior parte dos palpites de um "derrubador" terão sido derrotados. Para ficar mais claro, segue o exemplo com um jogo de "vencedor" (ou "ponta") em um páreo com nove cavalos. ${ }^{13}$ Levando em consideração que ele consiga convencer nove jogadores com um cavalo para cada jogador, oito de seus palpites serão "furados" e não ganharão o prêmio máximo. ${ }^{14}$

Por outro lado, valendo-se da etiqueta de retribuição de palpites, o jogador "derrubador" volta-se ao jogador com o palpite vencedor e menciona a praxe da retribuição (principalmente financeira), com algum percentual do prêmio aferido para quem "deu o cavalo" vencedor. Com isso, o jogador vencedor, mantendo a etiqueta dos apostadores, entregaria um percentual de seu prêmio como "retribuição obrigatória" (Mauss 2003 [1950]) pelo cavalo "dado". Os demais jogadores derrubados aceitam seu destino sob a bandeira conformista de que no turfe "ora se ganha, ora se perde" e o mais "infalível" dos palpites pode não "encaixar", e principalmente, de que a mudança de uma aposta para outra é realizada pelo próprio jogador e "ninguém obriga ninguém a jogar", muito menos a mudar uma aposta. Muitas vezes, uma "derrubada", principalmente quando se troca um cavalo vencedor por um perdedor, serve como alerta para um jogador de que não deve confiar mais na leitura de terceiros do que na sua própria. Sob esta perspectiva, raramente se busca tirar satisfação com quem passou uma informação errada. Com isso, Choppinho comenta o

13 É a modalidade de aposta mais simples. O apostador escolhe um cavalo e só ganha se ele chegar em primeiro lugar no páreo, sendo o valor apostado escolhido pelo turfista.

14 Um palpite pode ser vitorioso mesmo se o cavalo chegar em segundo, como no caso de um jogo de "placê", por exemplo; aqui exemplifico com a ideia dos jogos de "vencedor" ou "ponta" para simplificar o argumento. 
caso de Cabeleira, que havia recebido uma ligação de um contato de dentro do Jockey Club Brasileiro e realizado uma aposta de duzentos reais ( $\mathrm{R} \$ 200,00$ ) em um páreo, mas que se mostrou sem sucesso: "O Cabeleira, coitado, ele é muito derrubado. Tem mania de jogar alto, neguinho alarga o olho pra cima dele. Aí de vez em quando ele recebe uma furada dessas".

Nestes casos, um "derrubador" vai buscar dar o seu melhor palpite ao jogador que habitualmente gasta mais com cada aposta, visando uma retribuição maior. Deste modo, é possível observar um jogador "derrubador" não como aquele que almeja a derrota de seus companheiros de jogo, mas a sua vitória. Seus melhores palpites serão distribuídos para aqueles jogadores que gastam mais e que possivelmente retribuirão com valores mais altos. Os demais palpites serão distribuídos como uma forma de assegurar uma vitória a qualquer custo, principalmente às custas das apostas de seus companheiros de jogo. A distinção entre um jogador que passa palpites de maneira habitual e um que "derruba" está justa e sistematicamente na consistência dos palpites deste, considerados ruins ou com pouca aderência. ${ }^{15}$ Deste modo, o conceito de "derrubador" não é apresentado como uma forma de identidade, mas é uma categoria de acusação que reflete na reputação do jogador a partir de sua postura frente aos demais.

A troca de palpites e informações, as discussões e negociações referentes a um páreo são sistemáticas e recorrentes. Não apenas derrubadores, mas todos os jogadores, de maneira geral, irão defender seus cavalos até o final da corrida. E a retribuição, em muitos casos, pode também ser "um agrado", uma cerveja, favores como cafés e cigarros, ou até mesmo simbólicas, como o reconhecimento público de quem "deu" o palpite vencedor. A decisão de retribuir, e como fazê-lo, está inteiramente nas mãos do jogador vencedor e uma demanda enfática por retribuição financeira pode gerar conflitos, mal-estar e discussões entre os jogadores.

A exigência explícita e sistemática de uma retribuição de maneira considerada injusta ou desproporcional pode gerar conflitos e romper relações, como no exemplo de Marcão e Seu Pereira. Seu Pereira havia montado um jogo de acumulada conhecido como "pick 3" - uma modalidade em que o jogador escolhe o vencedor de três páreos, nos quais as indicações nos dois primeiros são obrigatórias e o terceiro páreo é livre para a escolha do jogador. A bonificação neste jogo é de $100 \%$. Antes do início da primeira corrida, Marcão

15 Creio existir uma distinção clara entre os termos "derrubador" e "barbadeiro", apresentado por Velasquez (2015) dentro dos portões do hipódromo da Gávea. Embora ambos sejam termos depreciativos e que remetem à distribuição de "barbadas", a sua distinção está no par ativo/passivo. Assim, um "derrubador" é aquele que intencionalmente oferece "barbadas" e informações de cavalos nos páreos. É ele que vai atrás, liga e "oferece" um cavalo em um páreo, sem que o jogador tenha questionado. Um "barbadeiro" encontra-se na espera de que alguém busque seus conhecimentos sobre os páreos. Apesar de suas distinções, ambas as categorias podem afetar a reputação de um jogador. 
convence Seu Pereira de que um dos seus cavalos não se consagraria vencedor. Segundo ele, uma "barbada" adquirida de um contato dentro do Jockey Club Brasileiro apontava que no segundo páreo a aposta deveria ser outra. Após um período de negociação, Seu Pereira se vê convencido de que sua aposta inicial estava equivocada e que deveria seguir o conselho de seu companheiro de jogo. A decisão de Seu Pereira foi correta - a dica de Marcão foi acertada -, e com isso ele ganha R\$ 14.000 com sua aposta de "pick 3".

"Paguei os 3 [mil] que devia aqui [na casa], deixei o das meninas, paguei ao Carlos [outro jogador] uma grana que devia e ainda dei 4 [mil] pro Marcão. O cara ficou puto e ficou falando por aí que eu tinha que ter dado metade e que sem a barbada dele eu não teria ganho. Pô, o cara quer gozar com pau dos outros! Não pode ficar feliz em ter ganho quatro contos [4 mil] sem ter levantado um dedo!? Isso não tá certo não, ninguém me obriga a dar a metade pra ele. Hoje em dia eu passo longe, já me estressei demais com esse papo".

A fala de Seu Pereira explicita que, mesmo "entregando" um cavalo vencedor, os critérios de retribuição são prerrogativas do apostador vencedor. Além disso, a fala evidencia a existência da "caixinha", ou "comissão", uma etiqueta retributiva que incide nos gastos e ganhos dos jogadores. Retribui-se a feitura de um jogo, a sorte e, finalmente, a vitória. A "caixinha" adquire valores simbólicos que vão desde um gesto de retribuição por um serviço prestado até a retribuição pela sorte e ganho de uma premiação considerada alta. Com relação à prática de se dar gorjetas, Viviane Zelizer (1994) explicita a evidenciação de uma etiqueta complexa inserida em diversos espaços em atividades distintas:

"Na verdade, a etiqueta da gorjeta tornou-se cada vez mais complexa, introduzida por questões não só de quanto se deve dar, mas a quem dar, quando dar, e como dar. Mas a gorjeta apresenta um quebra-cabeça fundamental: ela se insere no limite de outras transferências criticamente diferentes, não é bem um pagamento, não é bem um suborno, não é bem caridade, assim como não é bem um presente. A confusão se estende para os efeitos da gorjeta sobre a relação entre quem dá e quem recebe. [...] Diferente de pagamento, gorjeta, como explicou um especialista em etiqueta, serve para ‘lembrar' os que 'dão serviço pessoal'” (Zelizer 1994: 95).

Deste modo, a retribuição aos intermediários entre o jogador e o jogo faz parte de um código de etiqueta considerado como parte integrante do jogo. O antropólogo Rafael Velasquez, ao estudar os processos de trocas no turfe, argumenta: "Ao se dar uma 'barbada', não se verbaliza que se quer algo em 
troca, mas espera-se algo" (2015: 1 14). Além disso, o trecho narrado por Seu Pereira evidencia outra faceta importante do turfe, que é o conceito de "barbada" - um dos termos mais enigmáticos utilizados diariamente por jogadores de turfe. ${ }^{16}$

"Barbada" é o conceito utilizado quando um cavalo é considerado o mais apto a vencer o páreo. Como afirmou o jogador Verdura em uma das reunióes acompanhadas: “Esse ganha até com três pernas! É barbada certa!” Entretanto, a definição deste conceito se complexifica, pois não segue a mesma linha lógica de classificação de um cavalo favorito e mais apostado entre todos os jogadores. Um cavalo que não seja favorito pode se tornar uma "barbada", da mesma forma que um páreo com um "grande favorito" pode não se tornar uma. Ocorre que a grande maioria dos páreos não possui "barbadas", ou não tem jogadores que tenham "barbadas" a apresentar e oferecer. A chave de enunciação de uma "barbada" está na sua garantia de vitória, um cavalo "imperdível" ou uma aposta infalível. Ao contrário do que ocorre com um palpite convencional, a "barbada" possui um grau especulativo menor e com um traço marcante de previsibilidade do resultado final.

O jogador Cumprido, ao conversar sobre o campeonato nacional de futebol, afirma: "Amanhã o São Paulo é barbada!" O fato de ser o único são-paulino no grupo gerou discórdia e deboches quanto a sua afirmação. Entretanto, o jogador Eduardo se vira e comenta: "Esses caras acham que tudo agora é barbada. Não entendem nada mesmo”.

A crítica de Eduardo não se centrava no conteúdo da fala de Cumprido, quando clamou uma possível vitória de seu time de futebol como "barbada", mas na forma como uma parcela de jogadores concebe empregar esse conceito fora da atividade turfística, o que considera um equívoco. Se trata de uma certeza dentro de um universo de incertezas especulativas, certezas que só seriam possíveis de alcançar a partir de uma visão completa do jogo. A força da utilização do conceito de "barbada" é levada seriamente e não pode ser tratada com leviandade.

Uma definição pode ser encontrada em Velasquez, auxiliando à compreensão deste conceito:

16 Velasquez (2015: 105-116) discute o conceito de "barbada" em seu trabalho com o turfe no hipódromo da Gávea, no Rio de Janeiro, demonstrando claramente as características essenciais que lhe são atribuídas pelos jogadores, enquanto detentora de traços enigmáticos e constituída de "força social" (2015: 110). Entretanto, em seu processo de análise, trata-a como um "objeto" imaterial envolvido num circuito de dádivas, se desassociando por completo da ideia de "palpite" e deixando fora qualquer processo de negociação atrelado a ela. Para tanto, a "barbada" perderia sua característica paradoxal imanente de existir e não existir simultaneamente, pelo que a sua força se encontraria nos argumentos de quem afirma a sua existência. Assim, creio ser mais profícuo voltar o olhar para os processos de negociação envolvidos em sua construção. 
"Pode-se dizer que a barbada tem um efeito de predição (mas não de adivinhação) do futuro, de algo um pouco acima da incerteza, de um futuro (quase) inevitável. Ela é apenas e justamente revestida por essa aura. A barbada é como se fosse um palpite. Na verdade, ela é algo mais que um palpite. É uma informação encoberta pela ideia de privilégio, único e singular. O seu (pres)sentimento é mais forte do que a sua definição" (Velasquez 2015: 110 , grifos meus).

Desta forma, o conceito é utilizado parcimoniosamente, pois leva em conta uma garantia, exercida por quem a apresenta, de um "futuro inevitável". E uma quebra de uma "barbada", um resultado desfavorável, incide diretamente no status e na reputação do jogador e de sua rede de contatos. A frustração oriunda de se seguir uma "barbada" ruim é gerada pela ruptura das expectativas de certezas estabelecidas por esta enunciação, do mesmo modo que um jogador que sistematicamente apresenta "barbadas" ruins ou palpites falhos pode ser tido como um mau jogador, ou até mesmo como um "derrubador".

Assim, como um palpite, uma "barbada" pode surgir a partir do acionamento de uma rede de circulação construída pelo jogador, de onde ele irá adquirir privilegiadamente uma informação de caráter sigiloso, ou uma "informação de cocheira”. Cada jogador acionará as suas e cada rede pode abarcar outros jogadores, cavalariços, veterinários, até a mais alta hierarquia do Jockey Club Brasileiro, dos treinadores aos donos de haras e studs, chegando até a presidência do clube. Entretanto, como afirmou Velasquez: "Isso não significa que haja um consenso geral sobre o que é esse privilégio" (2015: 111 ). O privilégio insere-se na procedência de cada informação, que dependendo de sua origem é tida como mais confiável, forte ou vitoriosa.

A característica de segredo e a busca pelo sigilo encontram-se na mesma lógica de não difundir uma "barbada" entre um número grande de jogadores, pois, em última instância, aumentariam as apostas em um jogo e, consequentemente, o rateio seria feito entre um número maior de jogadores. ${ }^{17}$ Mesmo que raramente este seja o caso, por ter um estatuto de verdade, de certeza absoluta de vitória, o sigilo atribuído à troca de informações com "barbadas" é, na maioria das vezes, levado com mais seriedade do que nos palpites comuns, do mesmo modo que é evitada a sua difusão para que jogadores com disputas e desavenças não joguem e ganhem com elas.

17 Seja qual for a modalidade de aposta, os valores pagos por cada jogo serão baseados no rateio do volume total de apostas. A cotação do rateio referente a cada cavalo é extraída a partir da multiplicação do valor total apostado em um competidor pelo rateio pago por cada cavalo. Assim, quanto maior o número de apostadores, menores serão os valores pagos a cada um. 
Evitar a difusão das "barbadas" possui um segundo sentido, quando se mantém atrelada às expectativas oriundas da sorte, pois, como ocorre com seu prêmio pago, difundi-la pode levar a uma diluição da sorte, tendendo à sua extinção. Difundir uma "barbada" leva à diluição de sua força e suas garantias. Não se entrega de maneira aberta aos demais jogadores, pois corre-se o risco de estar entregando a sua própria sorte. Assim, manter o controle da divulgação das informações de uma barbada é imprescindível.

Além disso, ela pode estar fora de qualquer rede de informações. Um jogador, em geral mais experiente, pode acionar o enunciado de uma "barbada", mesmo que não tenha recebido informação de lugar nenhum. ${ }^{18} \mathrm{~A}$ subjetivação de uma "barbada" ocorre também nos casos em que o jogador se baseia em sua própria experiência. Na leitura objetiva do programa, nos seus conhecimentos de filiação e genealogia dos cavalos, da disposição dos animais na baliza, do número de treinadores e jóqueis num páreo e, em último caso, até em seu (pres)sentimento. Tais leituras de um determinado concorrente frente aos demais podem transformar simples palpites em "barbadas".

Assim como nem todo páreo possui uma "barbada", existem aqueles que possuem mais de uma. Isto é possível pois leituras distintas serão realizadas a partir dos mais diversos pontos de vista, ou então informações dissidentes e conflitantes poderão ser colhidas e contrastadas. Nestes casos, um extenso processo de negociação poderá ser acionado e as informações serão profundamente discutidas, a fim de se averiguar qual está "mais correta" a ponto de ser classificada como uma "barbada", processo que pode envolver uma gama maior de jogadores. Ao fim, não necessariamente exige-se um convencimento consensual; entretanto, o jogador que possuir argumentos mais fortes poderá sobressair perante o grupo. O processo de negociação e construção de uma "barbada" encontra-se na realização da aposta em si. Assim, ela não se apresenta completamente desvencilhada da noção de um palpite. Apesar de sua essência expor garantias no universo de incertezas das apostas hípicas, ela ainda é tida como um enunciado de um estatuto especulativo, cuja força muitas vezes estará na reputação do jogador que a apresentou e não na segurança de vitória - do mesmo modo que dar uma "barbada" ou recebê-la de bom grado de alguém também não é sinônimo de vitória instantânea no jogo, mesmo que o cavalo seja o vencedor do páreo.

A única modalidade em que uma "barbada" se transforma instantaneamente em uma vitória é num jogo de "vencedor" ou "ponta", modalidade com baixa adesão entre os jogadores, devido a sua fraca relação de custo-benefício. Aos que se consideram conhecedores do jogo, uma "barbada" é tida como mais uma fonte de construção de uma aposta e pode ser inserida em um acumulado

18 Ao contrário da noção de "barbadeiro", que distribui "barbadas" em todos os páreos e sempre terá uma "boa" para jogar. 
de páreos, combinada com outros cavalos ou (re)inserida dentro de uma gama de estratégias possíveis dentre as modalidades do turfe. Assim, por mais que o conceito seja atrelado a uma garantia de vitória, dependendo das escolhas e estratégias de cada jogador, a "barbada" pode não se materializar.

Por fim, existe um outro aspecto deste conceito que ainda falta ser explorado. Ao serem questionados sobre o significado de "barbada" nas carreiras do turfe, muitos dos jogadores são taxativos: "Barbada não existe!” Em uma conversa, dentre outras, que tive com jogadores em busca do entendimento deste conceito, Beto, Choppinho e Gigante são categóricos ao afirmar que "barbada" não existe. Seus discursos assumem que não há nada que possa ser infalível com as apostas hípicas, e que não é possível levar em conta uma garantia antes do fim de uma corrida. Com relação a isto, Gigante afirma: "Esse negócio não existe não. Você sabe prever o futuro? Aqui ninguém sabe, como é que querem dizer que é barbada?" Choppinho complementa: "Na hora do vamos ver é que o bicho pega. Já vi a melhor das barbadas não ser nem colocada. ${ }^{19}$ Depois ficam arrumando desculpa, porque perdeu. No fim, as corridas de cavalo se resumem na pista e não na cabeça do jogador". Por fim, Beto conclui: "Tem gente que fica [se] vangloriando de barbada depois do páreo, aí até eu! Isso tudo aí serve pra ficarem tirando onda com a cara dos outros e dizendo que sabem mais. Ninguém aqui tem bola de cristal. Depois que corre, todo mundo diz que já sabia".

A garantia de certeza atrelada ao uso deste conceito traz consigo uma descredibilidade e desconfiança dos demais jogadores. Ao acionar um enunciado de garantias dentro do turfe, a confiabilidade das informações poderá sempre ser posta em xeque pelo lado de uma "razão pura" (Sahlins 2003). Ora, nos diz Sahlins, essa elaborada autoconsciência de nossa sociedade, assumida acriticamente por tantas teorias, produz a cara ideia de que seríamos seres racionais governando nossas ações e instituindo cultura, sempre em busca da maximização de interesses materiais. Para o autor, essa visão é uma insidiosa manifestação da "razão prática", gerando não só um véu ideológico que a sociedade moderna lança sobre si, como também um equívoco conceitual estendido etnocentricamente a toda a humanidade. Apesar da forma imperativa como muitos afirmarão que "barbada não existe", isto não implica que os jogadores deixem de, em certa medida, utilizar este conceito com frequência. Momentos após a conversa mencionada acima com os três jogadores, escuto Beto afirmar para o jogador Tião: "No 7 tem barbada!" Assim, a existência

19 Se refere à colocação para uma corrida de grupo (G). Provas de grupo são consideradas mais exigentes e com competidores com níveis cada vez mais elevados. No calendário de provas da temporada 2014/15 (1. ${ }^{\circ}$ de julho de $2014-30$ de junho de 2015) foram corridas 28 provas de grupo l (G1), 33 de grupo 2 (G2) e 40 de grupo 3 (G3), com um total de 101 provas de grupo realizadas na temporada. Ainda foram realizadas 72 provas finalizando o calendário, com um total de 173 corridas ao todo, divididas pelos hipódromos da Gávea (RJ), Cidade Jardim (SP), Cristal (RS) e Tarumã (PN). 
de uma "barbada" não se resume a ser descoberta apenas no final da corrida. Como apontou Velasquez, "A barbada é palavra. Ela só se 'materializa' após o evento da corrida terminar. Antes disso não, é apenas esse poder, esse fascínio que exerce sobre si e sobre o outro" (2015: 133). Antes da corrida, a existência de uma barbada é ambígua e paradoxal; assim como o "gato de Schroedinger", ela está viva e morta, existe e não existe, simultaneamente no mesmo universo. E não se pode abrir a caixa antes do fim do páreo para se descobrir a sua real existência.

\section{CONCLUSÃO}

Nas casas de apostas, sobressair é ser reconhecido como o "conhecedor de cavalos" e, quanto a isto, o conhecimento do jogador perpassa um imbricado processo que vai do racional e objetivo ao metafísico e subjetivo. Nele estão as bases da obtenção de prestígio no grupo. Ter uma boa leitura do jogo e saber avaliar a totalidade das demais variáveis inseridas no universo do turfe são traços valorativos de um bom jogador. Tais processos de avaliação muitas vezes perpassam também pela subjetividade de cada um, criando múltiplos sistemas de representação e classificação de cada páreo. Assim, espera-se que um jogador tenha em seu olhar diferenciado o melhor foco para observar o universo do turfe por meio de suas próprias lentes. Que saiba de maneira equivalente enxergar tanto a ordem do universo abstrato quanto a ordem do universo dos sentidos, com o intuito de sobressair no jogo.

Assim como afirmei, o olhar diferenciado de cada jogador vai proporcionar que ele consiga adquirir palpites por meios intuitivos alcançados por intermédio do símbolo da sorte. A sorte, neste caso, se apresenta como uma força, é dotada de uma propriedade positiva. E somente com esse olhar treinado o jogador saberá avaliar a totalidade das variáveis envolvidas em cada corrida, incluindo no processo a avaliação da própria sorte, já que um jogador não deixa a sorte escapar e saberá medir o peso que ela trará em cada uma de suas jogadas.

Através deste trabalho realizado com jogadores nas casas de jogo foi possível observar que as apostas nas corridas de cavalos se apresentam como muito mais do que um fim em si mesmas. Uma aposta envolve um entrelaçamento de diversas variáveis, como conhecimento, relações de prestígio e relações de sorte, fatores conscientes e inconscientes negociados nestas arenas de sociabilidade. Deste modo, o turfe se comporta como atividade complexa com uma plurifatorialidade de itens e variáveis aparentemente desconexos entre si, cuja relação é dotada de sentido à medida que é classificada para as apostas. Enquanto cavalos correm, homens jogam e utilizam todas as nuances desta disputa para competir à espera da próxima vitória. 


\section{BIBLIOGRAFIA}

BARCElOS, Sergio, 2001, Cavalos de Corrida: Uma Alegria Eterna. Rio de Janeiro, Topbooks. CAILlois, Roger, 2001 [1958], Man, Play and Games. Urbana e Chicago, University of Illinois Press.

CASSIDY, Rebecca, 2002, The Sport of the Kings: Kinship, Class and Thoroughbred Breeding in Newmarket. Cambridge, Cambridge University Press.

CASSIDY, Rebecca, 2007, Horse People: Thoroughbred Culture in Lexington and Newmarket. Baltimore, MD, Johns Hopkins University Press.

DOUGLAS, Mary, 2010 [1979], Pureza e Perigo. Rio Janeiro, Editora Perspectiva.

GELL, Alfred, 1998, Art and Agency: An Anthropological Theory. Oxford, Clarendon Press.

LÉVI-STRAUSS, Claude, 1973, "A eficácia simbólica”, em C. Lévi-Strauss, Antropologia Estrutural. Rio de Janeiro, Tempo Brasileiro, 215-236.

MAUSS, Marcel, 2003 [1950], Sociologia e Antropologia. São Paulo, Cosac Naify.

MELO, Victor Andrade de, 2001, Cidade Esportiva: Primórdios do Esporte no Rio de Janeiro. Rio de Janeiro, Relume Dumará.

SAHLInS, Marshall, 2003, Cultura e Razão Prática. Rio de Janeiro, Jorge Zahar Editor.

SCOTT, Marvin B., 1968, The Racing Game. Chicago, Adeline Publishing Company.

VEBLEN, Thorstein, 1994 [1899], The Theory of the Leisure Class. Nova Iorque, Penguin Books.

VELASQUEZ, Rafael, 2015, Ciência Inexata. Niterói, Universidade Federal Fluminense, dissertação de mestrado.

VELHO, Gilberto, 2004, Individualismo e Cultura: Notas para Uma Antropologia da Sociedade Contemporânea. Rio de Janeiro, Jorge Zahar Editor.

ZELIZER, Viviana A., 1994, The Social Meaning of Money: Pin Money, Paychecks, Poor Relief \& Other Currencies. Nova Iorque, Basic Books. 